\title{
CONSERVADORISMO, AUTORITARISMO \\ E LEGITIMAÇÃO POLÍTICA DO ESTADO NOVO: NOTAS SOBRE OS "COMENTÁRIOS À CONSTITUIÇÃO DE 1937” DE PONTES DE MIRANDA
}

CONSERVATISM, AUTHORITARIANISM AND POLITICAL LEGITIMATION OF THE ESTADO NOVO: NOTES ON PONTES DE MIRANDA'S "OBSERVATIONS ABOUT THE BRAZILIAN CONSTITUTION OF 1937"

CONSERVATISME, AUTORITARISME ET LÉGITIMATION POLITIQUE DU ESTADO NOVO: NOTES SUR LES «COMMENTAIRES À LA CONSTITUTION DE 1937» DE PONTES DEMIRANDA

CONSERVADORISMO, AUTORITARISMO Y LEGITIMACIÓN POLÍTICA DEL ESTADO NUEVO: NOTAS SOBRE LOS "COMENTARIOS A LA CONSTITUCIÓN DE 1937" DE PONTES DE MIRANDA

\section{Luciano Aronne de Abreu ${ }^{1}$}

\section{Luis Rosenfield ${ }^{2}$}

Licença CC BY:

Artigo distribuído sob os termos Creative Commons, permite uso e distribuição irrestrita em qualquer meio desde que o autor credite a fonte original.

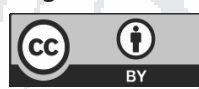

Resumo: Em que pese a vasta historiografia existente sobre o Estado Novo, o mesmo não se pode dizer a respeito da Constituição de 1937, sobre a qual os estudos existentes são ainda muito pouco numerosos. O eloquente silêncio a seu respeito talvez se deva a um comum desprezo de juristas e historiadores por essa Carta, geralmente vista como obra pessoal de Francisco Campos e mero instrumento de legitimação do regime. Ao contrário disso, porém, a Constituição de 1937 deve ser inserida no contexto mais amplo e complexo do debate político e jurídico que se travou no Brasil desde a década de 1920 a respeito da crise do liberalismo, de sua inadequação à realidade nacional e da formulação de um novo modelo político-institucional e jurídico para o país, de tipo autoritário e corporativista. Sob o ponto de vista estritamente jurídico e constitucional,

1 Professor do Programa de Pós-Graduação em História da Pontifícia Universidade Católica do Rio Grande do Sul (PUCRS) - luciano.abreu@pucrs.br.

2 Doutorando em Filosofia na Pontifícia Universidade Católica do Rio Grande do Sul (PUCRS) e em Direito na Universidade do Vale do Rio dos Sinos (UNISINOS) - luis.rosenfield@gmail.com. 
pode-se dizer que a Constituição de 1937 é uma não Constituição que se limitou ao período do Estado Novo e, ainda assim, sem que pudesse ter o seu modelo completamente implementado pelo regime. Já em termos políticos, pode-se dizer que essa Constituição representa, ao mesmo tempo, uma síntese e uma tentativa de institucionalização do pensamento conservador-autoritário brasileiro do período. Ao longo desse estudo, portanto, se propõe uma análise dos fundamentos de legitimidade jurídica e política da Constituição de 1937 sob o olhar de Francisco Cavalcanti Pontes de Miranda (1892-1972), um dos principais juristas contemporâneos brasileiros e dos poucos comentadores daquela Carta.

Palavras-chave: Constituição de 1937; Pensamento Constitucional; Pontes de Miranda; Constitucionalismo Autoritário; A Ditadura do Estado Novo.

Abstract: Despite the vast historiography that exists on the brazilian Estado Novo [New State], the same can not be said about the Brazilian Constitution of 1937, about which there have been very few studies. The eloquent silence about it may be due to a common disregard of jurists and historians for this Charter, generally seen as the personal work of Francisco Campos and a mere instrument for legitimizing the regime. On the contrary, however, the 1937 Constitution must be inserted in the broader and more complex context of the political and juridical debate that has taken place in Brazil since the 1920s on the crisis of liberalism, its inadequacy to the national reality, and the formulation of a new political-institutional and legal model for the country, of an authoritarian and corporatist type. From a strictly legal and constitutional perspective, it can be said that the 1937 Constitution is a NonConstitution that was limited to the period of the Estado Novo, and yet its model could not be fully implemented by the regime. In political terms, it can be said that this Constitution represents both a synthesis and an attempt to institutionalize Brazilian conservative-authoritarian thought of the period. This study therefore proposes an analysis of the foundations of legal and political legitimacy of the Constitution of 1937 through the work of Francisco Cavalcanti Pontes de Miranda (1892-1972), one of Brazil's leading contemporary jurists and one of the few commentators of that Charter.

Keywords: Brazilian Constitution of 1937; Constitutional Thought; Pontes de Miranda; Authoritarian Constitutionalism; The Dictatorship of the Estado Novo.

Résumé: Malgré la vaste historiographie existant sur le Estado Novo [Nouvel Etat], on ne peut pas dire autant de la Constitution brésilienne de 1937, dont les études existantes sont encore très peu nombreuses. Cet éloquent silence peut être dû au mépris commun des juristes et des historiens sur cette Constitution, généralement considéré comme le travail personnel de Francisco Campos et un simple instrument de légitimation du régime. Au contraire, cependant, la Constitution de 1937 doit être insérée dans le contexte plus large et plus complexe du débat politique et juridique qui a eu lieu au Brésil depuis les années 1920 sur la crise du libéralisme, son insuffisance pour la réalité nationale et la formulation d'un nouveau modèle politique-institutionnel et juridique pour le pays, d'un type autoritaire et corporatiste. D'un point de vue strictement juridique et constitutionnel, on peut dire que la Constitution de 1937 est une Non-Constitution qui se limitait à la période du Estado Novo et qui n'a pas eu la possibilité d'être pleinement mis en œuvre par le régime. Sur le plan politique, on peut dire que cette Constitution représente, en même temps, une synthèse et une tentative d'institutionnalisation de la pensée conservatrice-autoritaire brésilienne de l'époque. Tout au long de cette étude, on propose une analyse des fondements de la légitimité juridique et politique de la Constitution de 1937 à travers le travail de Francisco Cavalcanti Pontes de Miranda (1892-1972), l'un des principaux juristes contemporains du Brésil et l'un des rares commentateurs de cette Constitution. 
Mots-clés: Constitution de 1937; Pensée Constitutionnelle; Pontes de Miranda; Constitutionnalisme Autoritaire; la dictature de l' Estado Novo.

Resumen: A pesar de la vasta historiografía existente sobre el Estado Nuevo, lo mismo no se puede decir en relación a la Constitución de 1937, sobre la cual los estudios existentes son aún muy poco numerosos. El elocuente silencio sobre él, tal vez se deba a un común desprecio de juristas e historiadores por esta Carta, generalmente vista como obra personal de Francisco Campos y mero instrumento de legitimación del régimen. Al contrario de esto, la Constitución de 1937 debe ser inserida en el contexto más amplio y complejo del debate político y jurídico que se trabó en Brasil desde la década de 1920 con relación a la crisis del liberalismo, de su ineptitud a la realidad nacional y de la formulación de un nuevo modelo político-institucional y jurídico para el país, de tipo autoritario y corporativista. Sobre el punto de vista estrictamente jurídico y constitucional, se puede decir que la Constitución de 1937 es una no Constitución que se limitó al período del Estado Nuevo y, aun así, sin que pudiera tener su modelo completamente implementado por el régimen. Ya en términos políticos, se puede decir que esta Constitución representa, al mismo tiempo, una síntesis y una tentativa de institucionalización del pensamiento conservador-autoritario brasileño del período. A lo largo de este estudio se propone un análisis de los fundamentos de legitimidad jurídica y política de la Constitución de 1937 sobre la mirada de Francisco Cavalcanti Pontes de Miranda (1892-1972), uno de los principales juristas contemporáneos brasileños y de los pocos comentadores de aquella Carta.

Palabras clave: Constitución de 1937; Pensamiento Constitucional; Pontes de Miranda; Constitucionalismo Autoritario; La Dictadura del Estado Nuevo.

\section{INTRODUÇÃO}

A Revolução de 1930, segundo interpretação corrente da historiografia brasileira, simboliza a ruptura do modelo jurídico-político da Primeira República (1889-1930) - marco simbólico da derrocada do liberalismo político instituído com a queda do Império -, dando fim a quatro décadas de experiência de liberalismo político. Após fortes turbulências políticas e militares na década de 20, a tônica principal do discurso de Getúlio Vargas e dos intelectuais ligados ao seu regime seria a crítica ao liberalismo político e jurídico da Primeira República e a proposta de um modelo de constitucionalismo antiliberal, cujo símbolo e síntese podem ser identificados na Constituição de 10 de novembro de 1937, documento maior do seu projeto ditatorial.

Nesse sentido, um dos principais objetivos do varguismo era derrubar os alicerces do regime liberal então vigente no país e criar as condições que entendia serem necessárias para o seu desenvolvimento econômico, estabilidade 


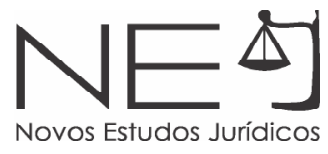

institucional, segurança nacional e para a proteção social da população brasileira3 . Para os homens que pensaram e conceberam o regime de Vargas, sobretudo nos tempos do Estado Novo, o dirigismo estatal seria a solução para muitos dos males da nação: a Primeira República, como dizia Oliveira Viana, seria marcada pelo "idealismo utópico" do seu modelo político-jurídico-institucional, mera "cópia das instituições europeias", ao contrário do seu projeto "realista", por ele definido como um "idealismo orgânico", devidamente adequado às peculiaridades sociais e culturais brasileiras.

A esse respeito, contudo, apesar das marcas ainda evidentes do varguismo no Brasil contemporâneo e dos inúmeros estudos existentes a seu respeito nos campos da História, do Direito, da Economia e outros tantos, é curioso o comum desprezo de historiadores e juristas a respeito da Constituição de 1937, sendo raros e limitados os estudos específicos sobre essa Carta Constitucional mesmo após cerca de 80 anos de sua outorga. Talvez esse desprezo se deva não à sua origem outorgada, em si, o que também foi o caso da Constituição de 1824, mas à sua suposta falta de legitimidade jurídica e política. Para uns e outros, historiadores e juristas, sejam eles contemporâneos ou não à Constituição, sua falta de legitimidade não apenas justificaria o desprezo por esse documento como também demonstraria o seu caráter limitado como fonte para a compreensão do Estado Novo de Vargas e seu modelo político autoritário e corporativo (ABREU, 2016, p. 463-464). Nas palavras de Walter Costa Porto (2001, p. 14), o grande obstáculo "para o exame da Constituição de 10 de novembro de 1937 é exatamente essa 'falta de respeito' que lhe devota o meio político e, afinal, a falta de isenção dos analistas, raros, de seu conteúdo".

Pode-se dizer que juristas e historiadores mantêm um eloquente silêncio a respeito da Constituição de 1937, tida como mero instrumento de legitimação do regime de Vargas. Ocorre, entretanto, que a Constituição de 1937, para sua melhor compreensão, deve ser inserida no contexto mais amplo e complexo do debate político e jurídico que se travou no Brasil desde a década de 1920 a respeito da crise do liberalismo, de sua inadequação à realidade nacional e

$3 \quad$ Nesse sentido, por exemplo, Oliveira Viana dizia que os direitos civis são mais importantes do que os direitos políticos. A esse respeito, ver: VIANA, Oliveira. O idealismo da Constituição. Rio de Janeiro: Terra do Sol, 1927. 
da formulação de um novo modelo político-institucional e jurídico para o país, de tipo autoritário e corporativista. Em termos políticos, entende-se que essa Constituição representa, ao mesmo tempo, uma síntese e uma tentativa de institucionalização do pensamento conservador-autoritário brasileiro do período. Já em termos jurídicos, pode-se definir a Constituição de 1937 como uma não Constituição, limitada aos anos do Estado Novo e, ainda assim, sem que o seu modelo fosse completamente implementado pelo regime. De um lado, portanto, a Constituição de 1937 representou um importante momento de institucionalização política do Estado Novo, sendo a data de sua outorga a mesma de início do novo regime; de outro, representou também uma síntese das principais ideias jurídico-políticas defendidas por importantes intelectuais conservadores da chamada "geração dos anos 1920-40" (PÉCAUT, 1989), tais como Oliveira Viana e seu próprio autor, Francisco Campos.

Nesse sentido, esse estudo tem por objetivo justamente analisar, em termos políticos, o caráter supostamente democrático e corporativo atribuído por Oliveira Viana e Francisco Campos ao Estado Novo e à sua Constituição e, em termos jurídicos, à falta de institucionalidade jurídica desse documento (ou os seus novos e excepcionais fundamentos), tendo por base o pensamento de Francisco Cavalcanti Pontes de Miranda (1892-1972)4 , o principal comentador da Constituição de 1937.

A respeito desses intelectuais, ainda que eles tenham em comum uma sólida formação e atuação jurídica, anterior ou posterior ao regime, deve-se observar que cada um deles manteve com o Estado Novo diferentes formas de relação. No caso de Francisco Campos, Ministro da Justiça (1937-1943) e autor da Constituição de 1937, sua atuação é geralmente vista pela historiografia não apenas como jurista, mas especialmente como um dos principais ideólogos do regime; Oliveira Viana, embora também incluído entre os seus ideólogos, é destacado pela historiografia por sua atuação na construção da legislação social do regime, na condição de Consultor Jurídico do Ministério do Trabalho (1932-1940), e por

4 Durante os anos Vargas, foram publicados apenas o primeiro e o terceiro volumes da extensa obra de Pontes de Miranda sobre o arcabouço jurídico do Estado Novo, intitulada "Comentários à Constituição Federal de 10 de novembro de 1937". Especula-se que os volumes segundo e quarto, inicialmente previstos pelo autor, jamais chegaram ao público por terem sido censurados e queimados pelo Departamento de Imprensa e Propaganda (DIP), supostamente por conterem críticas aos procedimentos do Poder Executivo e à não realização do plebiscito previsto no artigo 187 da Carta Outorgada (Limongi, 1998, p. 125), sendo este episódio pouco documentado e praticamente desconhecido pela historiografia brasileira. 


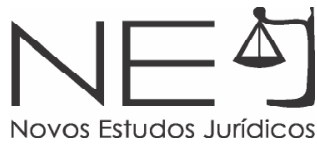

sua extensa obra de caráter histórico-sociológico, como se verá melhor adiante; Pontes de Miranda, por sua vez, era já naquele tempo reconhecido como um técnico, jurista por excelência, com vasta obra de doutrina jurídica em diversos campos do direito.

\section{FUNDAMENTOS POLÍTICO-DOUTRINÁRIOS DO REGIME}

Especialmente a partir da década de 1920 houve uma forte preocupação nos meios políticos e intelectuais brasileiros em encontrar as origens do atraso brasileiro e em apontar alternativas para superar tais males. Com isso, a chamada geração dos anos 1920-40 tentou auxiliar o Estado brasileiro na construção de uma nova sociedade em bases racionais, supostamente científicas e adequadas à realidade nacional. Naturalmente, esses intelectuais pertenciam à elite dirigente, e pode-se dizer que Oliveira Viana e Francisco Campos seriam dois dos seus mais importantes representantes, tanto por suas produções intelectuais como pelos altos cargos que ocupariam, posteriormente, durante o Estado Novo.

Oliveira Viana foi o intelectual que procurou proporcionar uma roupagem científica mais apurada aos seus estudos histórico-sociológicos sobre a formação do Brasil e a raiz dos seus problemas. Na opinião do autor, os limites impostos pela Constituição de 1891 ao poder central e a ausência de um líder forte e moderador do jogo político seriam os principais problemas da República no Brasil, cujo modelo democrático-liberal seria inadequado à realidade nacional, mero idealismo utópico baseado em fórmulas estrangeiras. Nesse sentido, diz ele: "Veio a República. Veio a Democracia. Veio a federação. E para logo se levantou um sussurro de desapontamento do seio da turba fanatizada - e esse desapontamento se acentuou, com o tempo, numa permanente desilusão" (VIANA, 1923, p. 28-29).

A superação desses problemas, no entanto, dado que o espírito de clã se constituiria na base da organização social brasileira, seria algo muito mais complexo do que simplesmente realizar uma reforma constitucional ou política no país. Ao contrário disso, as reformas constitucionais seriam para Oliveira Viana apenas meios auxiliares de outras reformas maiores, "de caráter social 
Novos Estudos Jurídicos

e econômico, que devemos realizar, se quisermos estabelecer aqui o 'regime democrático', o 'regime de opinião', o 'regime do governo do povo pelo povo'" (VIANA, 1923, p. 64). Para Viana, a democracia se caracteriza como "governo da opinião", e essa organização pode se dar mesmo sem a existência de partidos políticos, de eleições ou do voto, pois o sentido nacional da revisão no Brasil iria muito além de uma eventual nova constituição para o país (ABREU, 2016, p. 465). Com isso, Viana apostava no fortalecimento do Executivo e do Judiciário, em contraponto à tradição de protagonismo do Legislativo, que deveria ser colocado em posição subalterna, em razão de sua importância secundária: "O Poder Legislativo (na sua modalidade parlamentar) é, ao contrário do que parece, de importância secundária. Um Poder Executivo forte; ao lado dele e contra ele, um Poder Judiciário ainda mais forte - eis a fórmula" (VIANA, 1930, p. 62). Aliada a essa concepção antiliberal de redução das liberdades individuais e de reorganização da estrutura constitucional, especialmente no que se refere à separação dos poderes, propunha um novo modelo corporativo no qual as classes econômicas participariam dos negócios públicos:

Uma democracia só é realmente digna deste nome quando repousa, não só na atividade dos seus cidadãos, agindo como tais, isto é, como indivíduos; mas na atividade dos seus cidadãos agindo como membro desta ou daquela corporação, como parcelas de um agrupamento, unidos pela consciência de um interesse comum, de classe (Viana, 1930, p. 119-120).

A defesa das corporações e da consciência de um interesse comum (ou seja, de um interesse de classe) será um dos pontos distintivos do pensamento de Viana e uma das bases de sua crítica à democracia parlamentar e ao liberalismo. De mesma forma, Francisco Campos também possuía ojeriza à "teologia liberal" e, consequentemente, afirmava a necessidade de se construir no Brasil um novo regime de opinião que prescindisse de partidos políticos, de eleições e do voto (ABREU, 2016, p. 466). Por um lado, Getúlio Vargas exerceu o poder de forma extremamente pragmática, com tintas populistas, com intuito estratégico de acalmar as numerosas forças antagônicas que cercavam seu governo, para assim se manter no poder perpetuando um projeto de estado forte e centralizado. A 
construção legislativa por ele orientada - e levada a cabo por seus ideólogos durante o Estado Novo estruturou um direito de viés conservador, autoritário e corporativista. Havia pouco ou nenhum espaço para a política partidária, vista como sectária e desagregadora. O constitucionalismo antiliberal varguista seguiu a onda que tomou conta de muitos países da América Latina à época, mostrando um perfil social em matéria de direitos contraposto a um caráter conservador no que se refere à organização do poder (GARGARELLA, 2013, p. 84-130).

Basta lembrar que nas décadas de 1920, 1930 e 1940 que se começou a apostar na negação aos partidos políticos e ao dissenso democrático. Com a queda da democracia representativa, o Estado Novo consagrou um sistema regulatório autoritário, conservador e corporativo em que o processo de modernização ocorria de cima para baixo, com a outorga de direitos. Nesse contexto, foi afirmada uma forte convicção antijudiciária, e os juristas ligados ao regime, cujos expoentes são Oliveira Viana e Francisco Campos, forneceram novos contornos à interepretação jurídica, demonstrando intensa repulsa ao "formalismo jurídico" e ao "idealismo constitucional". São controvérsias que frequentemente voltam ao centro dos debates nas últimas décadas no Brasil. Os ecos dos jurisconsultos que construíram suas carreiras e ganharam prestígio naquela época ainda se fazem ouvir. A extensa vertente do que se pode chamar de doutrina antiliberal do direito, composta por nomes como Monte Arraes, Gustavo Barroso, Anor Butler Maciel, Miguel Reale, Francisco Brochardo da Rocha, Eurico Castello Branco e Raul Machado, entre muitos outros, atuou intensamente na primeira metade do século XX e deixou evidentes rastros no desenvolvimento constitucional brasileiro.

Para Francicos Campos, vivia-se numa época de transição, "em que o passado continua a interpretar o presente", pois o "presente ainda não encontrou suas formas espirituais". Nesse cenário, "as formas espirituais do passado" são tidas como "inadequadas, obsoletas ou desconformes" (CAMPOS, 1940, p. 5), pois, no mundo moderno, as soluções que até então "constituíam nossa herança intelectual, política e moral" se transformaram em problemas, devendo a educação ser "uma educação para problemas, e não para soluções, não para este ou aquele regime de vida, pois não se sabe ou não se acredita saber em que quadro de linhas 
móveis e flutuantes irá o homem viver" (CAMPOS, 1940, p. 6). Para o pensamento político-jurídico autoritário do período, com o advento das massas e sua entrada no mundo político, a esfera pública se tornou irracional, ocorrendo o consequente divórcio entre democracia e liberalismo. Dessa maneira, existe a necessidade dessas massas serem integradas politicamente, pois quanto maiores deverão ser os instrumentos espirituais da integração total com o projeto estado-novista:

A política transforma-se dessa maneira em teologia. Não há formas relativas de integração política, e o homem pertence, alma e corpo, à nação, ao Estado, ao partido. As categorias da personalidade e da liberdade são apenas ilusões do espírito humano (CAMPOS, 1940, p. 12-13).

Essa "nova democracia" - ao contrário do seu conceito negativo do século XIX, que impunha limites à atuação do Estado - tinha um sentido positivo, de assegurar aos homens o gozo de novos direitos, devendo o Estado ser forte o suficiente para garantir sua efetividade, exercendo "de modo efetivo o controle de todas as atividades sociais - a economia, a política, a educação" (CAMPOS, 1940, p. 56). Paradoxalmente, ao mesmo tempo em que Campos e Viana defendiam a ditadura varguista quase que irrestritamente, esses intelectuais tinham pouco apreço pelas normas instituídas pela Constituição de 1937, que, embora tenha marcado a institucionalização política do Estado Novo, não seria ela própria institucionalizada durante todo o seu período de vigência. Para Campos, a Constituição era apenas um dos elementos do poder político, mais importante que ela seria a organização sólida e estável da liberdade civil e, mais importante, o reforço da autoridade do poder central (CAMPOS, 1940, p. 21). Embora a Constituição de 1937 previsse sua legitimação por meio de um plebiscito em seu artigo 187, esses intelectuais entendiam que o poder constituinte do novo regime não seria dado pela participação direta e individual do povo, mas pela integração política das massas ao Estado, em nome da nação e dos seus interesses coletivos. Porém, como bem definiram os professores da Faculdade Nacional de Direito, a Constituição de 1937 acabou por se constituir apenas numa norma de fato, carente de legitimidade jurídica e política, "a que não resta outra existência senão a da força que a mantém". ${ }^{5}$

$5 \quad$ Parecer publicado no jornal Correio da Manhã no dia 3 de março de 1945. Texto integral também disponível em Porto (2001). 


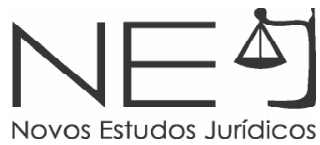

No caso de Pontes de Miranda, como se verá melhor no decorrer desse estudo, sua visão sobre o golpe do Estado Novo e sobre a legitimidade de sua Carta outorgada é mais obscura e nuançada do que as ideias anteriormente referidas de Viana e Campos. Sua doutrina persegue um percurso argumentativo mais acidentado, em um estilo supostamente mais "lógico" e "técnico" do que o dos ideólogos do regime que, de certa forma, esconde sua opinião sobre os turbulentos acontecimentos do período.

\section{FUNDAMENTOS CORPORATIVOS DE UMA NOVA “DEMOCRACIA”}

No ambiente autoritário, conservador e antiliberal da Europa do entreguerras, buscou-se esfarelar a organização liberal das sociedades em nome da proteção da coletividade, num momento decisivo de contestação da democracia parlamentar, em que o comunismo, o nazismo e o fascismo se apresentam como alternativas às crises do liberalismo político e do liberalismo econômico. Como visto anteriormente, por meio da tinta dos dois principais intelectuais do Estado Novo, o Brasil fez uso de diversos remédios autoritários para dar continuidade a um projeto de poder. As críticas ao modelo de democracia representativa foram amplificadas com a Crise de 1929 e a tomada de poder na Europa da década de 1930 de regimes autoritários e totalitários, ainda sob a sombra também da Revolução Russa de 1917. No que se refere à estrutura constitucional do varguismo, as análises jurídicas da Constituição de 1937 feitas nas salas de aula das faculdades de Direito atualmente se resumem, com frequência, a rotular tal carta constitucional apenas como um documento ditatorial ou, pura e simplesmente, a referi-la pelo seu apelido, a "Polaca", em referência à Constituição Polonesa do ditador Józef Pilsudski.

Apesar de sua falta de legitimidade, pode-se afirmar que a Constituição de 1937 contribuiria para o processo de institucionalização e legitimação política do Estado Novo no Brasil, justificando desde o seu preâmbulo até a necessidade de se introduzir no país um governo forte e nacionalista como uma resposta às "legítimas aspirações do povo brasileiro" e ao "estado de apreensão criado no país pela infiltração comunista". Em igual sentido, dada a gravidade da situação, a própria Constituição, em suas Disposições Transitórias e Finais, decretaria em 
Novos Estudos Jurídicos

todo o país o estado de emergência (art. 186), em vez de apenas autorizar o presidente a fazê-lo, como nas constituições anteriores de 1891 e de 1934.

A elite jurídica dos anos 30 e 40 que orbitava em torno do projeto varguista se diferenciava da geração anterior pelo seu caráter mais incisivo nas propostas de reformulação da estrutura do estado. Trata-se de um vasto grupo de juristas comprometidos em encontrar uma solução genuinamente brasileira, que se insurgia pelo que entendia como mera importação sem filtros das experiências norte-americanas e europeias. $E$, de fato, é difícil não reconhecer a influência dos homens fortes da teoria do estado e do direito constitucional daqueles anos para a contemporaneidade, os quais defendiam - com todas as letras - a democracia autoritária, eugênica e corporativa (VIANA, 1955, p. 427). Uma das insurgências de Oliveira Viana contra Rui Barbosa consistia na crítica de que o jurista baiano havia simplesmente importado os institutos jurídicos norte-americanos para o Brasil sem perceber as peculiaridades da realidade nacional, deixando bem claras suas opções intelectuais pela via autoritária para o desenvolvimento político brasileiro. Para Viana, os novos tempos demandavam

[...] considerar os problemas do Estado ou, melhor, os problemas políticos e constitucionais do Brasil, não apenas como simples problemas de especulação doutrinária ou filosófica - como então se fazia e como era o método de Rui; mas como problemas objetivos, vinculados à realidade cultural do povo (VIANA, 1955, p. 425).

As ácidas críticas de Viana, de certa forma, caricaturavam a geração que o precedeu: descreveu Pedro Lessa, na sua obra "Instituições políticas brasileiras", como um "sonâmbulo judicial" em razão da farta utilização por Lessa de conceitos jurídicos norte-americanos e ingleses ("autonomia local", "self-government", "habeas corpus", etc.), colocando que "no espírito desse grande mestre (...) o Brasil ou o povo brasileiro não existia como realidade objetiva" (VIANA, 1955, p. 425). Dessa forma, o "realismo" de Oliveira Viana propunha que o Brasil não precisa de um partido único, como nos casos de Alemanha e Itália, e sim de um presidente único, ou seja, "do Presidente que não divida com ninguém a sua autoridade; do Presidente em quem ninguém mande; do Presidente soberano, exercendo, em suma, o seu poder em nome da nação, só a ela subordinado e só dela dependente" 


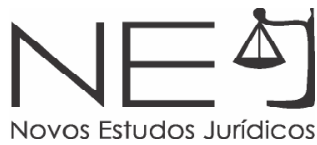

(VIANA, 1939, p. 207). Viana trabalhava fortemente para legitimar o Estado Novo no plano teórico: em sua opinião, o ideal de um presidente armado dos poderes excepcionais previstos pela Constituição de 1937 não seria o de um chefe de partido, e sim o de uma autoridade que se colocasse acima dos partidos e dos grupos de qualquer natureza, "de modo a poder dirigir a nação do alto, num sentido totalitário, agindo como uma força de agregação e unificação - e não como uma força de desagregação e de luta" (VIANA, 1939, p. 208).

As propostas teóricas de reorganização constitucional propostas por Viana e Campos encontraram adeptos para sua adoção e posterior sistematização doutrinária. Desde pelo menos meados da década de 1920, Pontes de Miranda também abraçava a convicção corrente sobre a necessidade de se estabelecer uma "política scientífica", voltada à racionalização do uso do poder estatal, pois "a sciencia é um dos instrumentos da diminuição do despotismo", pois a "diminuição do despotismo torna possível e facilita a intervenção da sciencia no trato dos problemas sociais e políticos" (PONTES DE MIRANDA, 1924, p. 239). Nesse sentido, a busca por uma política científica nos anos 1920 estava inserida num horizonte mais amplo em que ainda se destacava o "naturalismo jurídico" da Primeira República. Antes da Revolução de 30 já existia uma mentalidade cientificista, principalmente a partir de Herbert Spencer, que permeava o pensamento de Pontes de Miranda (LOPES, 2014, p. 31-46).

Pontes de Miranda nutria essa "nova fé" na ciência como força motriz da mudança social, política e jurídica no país, e esse processo irá ganhar ainda mais ímpeto a partir do começo da década de 1930 em diante. No contexto de aguda crise do estado nos planos doméstico e internacional, Pontes apontava que a democracia era apenas "fórma", e não "conteúdo", e era precisamente essa a razão de seu fracasso. No plano da "codecisão democrática", existia o problema da "revisibilidade livre dos valores", pois a "decadência da democracia deriva" de "haverem as massas descoberto que a codecisão democrática, por si só, não consegue fixar o que deve querer". Ou seja, para Pontes "póde-se definir a democracia como o regime da discussão sobre tudo, o systema político (quasi disse 'apolítico') da provisoriedade de todos os fins do Estado". Dessa forma, 
assim se referindo ao conceito de democracia, afirma que "rigorosamente, quem diz Estado de fins mutáveis, provisórios, diz Estado sem fins". Esse processo de maior envolvimento do jurista Pontes de Miranda com a questão da democracia evidencia a vontade de encontrar respostas claras para a crise política que o país atravessava (PONTES DE MIRANDA, 1933, p. 12-14) (grifos originais).

Em determinados escritos de Pontes de Miranda, anteriores à outorga da Constituição de 1937, observa-se a convicção do autor em negar a democracia parlamentar, apostando na proposta corporativista, na planificação econômica e no que ele chamava de "revolução de estrutura" (PONTES DE MIRANDA, 1933, p. 10-18). Dentro do caldeirão de ideologias daqueles anos, acreditava em um "novo conteúdo" e numa "nova forma do Estado", e isso envolvia um Estado ocupado em "questões substanciais", pois "o fim do Estado tém de ser substancial e envolvente, não póde ser formal e envolvido" (PONTES DE MIRANDA, 1933, p. 20). Na prática, isso significava para Pontes um claro divórcio com os "idealistas" da geração anterior, que possuíam fé nas reformas da constituição e/ou na substituição dos dirigentes políticos. Dessa maneira, a questão se resumia em reduzir o Estado à "technica social", em encontrar fins precisos para a atividade estatal que levassem ao bem comum:

A questão pôde ser posta a posteriori: os Estados antigos, os Estados modernos e os Estados recentes, como o soviético e o fascista, têm fins communs, immutaveis, ou ha fins differentes nelles? O mais que podemos apurar, se queremos ver objetivamente, é que o Estado constitúe, por si, um methodo, uma technica social. Em cada um dos Estados há fins preponderantes: em alguns, são mais precisos do que noutros: formaes aqui, substaciaes além. O Estado de fins nitidos, homogeneos, coherentes, mais se accentúa nos nossos dias, com a Russia, cuja univocidade submete toda a actividade social a uma direção rija e inamolgavel, e talvez seja o do Estado technico-syndicalista a surgir em alguns países. Como quer que seja, assistimos a um processo de clareiamento e precisão dos fins, senão do fim primordial do Estado. Talvez a única solução para o problema da adhesão à nova ordem social esteja na confiança em tender o Estado a fins precisos e finalmente inteligíveis (PONTES DE MIRANDA, 1933, p. 21-22) (grifos originais).

Como visto anteriormente, ele partilhava da desilusão com as "promessas legaes", filiando-se à vertente "realista" que possuía o "temor de que tudo 


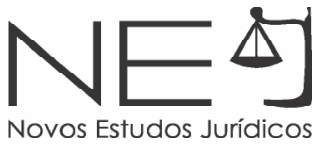

se reduza a construcções jurídicas sem apoio e sem actuação na vida", pois o caminho que devia ser trilhado deveria ter "fins precisos e economia dirigida ou de plano" (PONTES DE MIRANDA, 1933, p. 28-29). Assim, percebe-se aqui a gênese da democracia autoritária e corporativista em Pontes, e o que isso acarretará em sua concepção sobre a revolução jurídica e política do Estado Novo. Nas encruzilhadas ideológicas de seu tempo, Pontes de Miranda colocou o Brasil no dilema entre a "reviravolta prevista por Marx" ou "o novo Estado anti-individualista" (PONTES DE MIRANDA, 1933, p. 36); tendo optado por um caminho do meio que descreveu como um "Estado Socialista" sem derramamento de sangue (PONTES DE MIRANDA, 1933, p. 96). Entretanto, percebe-se que, diante do fato consumado do Estado Novo, sua "análise técnica" da Constituição de 1937 pendeu para a adoção ao constitucionalismo antiliberal varguista, como se verá a seguir, e não tanto ao socialismo.

\section{FUNDAMENTOS JURÍDICOS DA NÃO CONSTITUIÇÃO DE 1937}

Apesar dos esforços dos juristas para legitimar a Constituição de 1937 e sua concentração de poderes como juridicamente válidas e adequadas à realidade nacional, é evidente que uma Constituição que supõe haver um poder superior a ela - o do presidente da República - só pode ser definida como uma não Constituição, por não emanar, como define a teoria constitucional, de um poder constituinte, e sim do arbítrio de um regime de exceção. Em tal perspectiva, podese dizer que o caráter democrático da Constituição de 1937 residiria, segundo os seus entusiastas e ideólogos do regime, em seus variados apelos à opinião popular, por meio de plebiscitos, e em sua defesa dos interesses coletivos, por meio das corporações. Ao longo de todo o regime, porém, nenhum desses plebiscitos jamais foi convocado pelo Presidente da República, sempre se valendo das já citadas prerrogativas do seu poder pessoal que a própria Constituição havia lhe conferido. $O$ mesmo se pode dizer em relação ao seu caráter corporativo, deixado à legislação ordinária e jamais regulado pelo governo, apesar da criação do Conselho de Economia Nacional, como bem observou Pontes de Miranda (1938, p. 25). 
Seguindo o ideal autoritário e coporativista que contaminou a intelectualidade entre as décadas de 1920 e 1940, Pontes de Miranda também negará a democracia parlamentar e a política partidária típica do liberalismo, apostando na "Política Científica que não é predomínio, mas administração, que não é explicação, mas cultura e valorização do homem". Em 1924 ele apresentou um programa para a revisão constitucional, colaborando para o debate que transcorreria no Congresso Nacional entre 1924 e 1926, culminado na extensa Revisão Constitucional de 1926. Segundo o jurista alagoano, o "Sindicalismo e o cooperativismo devem fundir-se numa só doutrina política, porque se completam, - não se contradizem. Construir é o ideal comum: que o cooperativismo se torne sindicalista e aproveite as vantagens das cooperativas, o sindicalismo". (PONTES DE MIRANDA, 1981, p. 17-18).

Nesse sentido, de acordo com o espírito do seu tempo, ao longo das décadas de 20, 30 e 40, Pontes de Miranda buscou também compreender os males originários do Brasil e chegou a apontar a questão racial como um dos componentes do atraso e da miséria, tratando a "cultura eugênica" e um tipo de socialismo moderado como possíveis soluções para os problemas sociais (PONTES DE MIRANDA, 1981, p. 10), buscando assim estabelecer os alicerces da solidariedade social em um país tão desigual como o Brasil (PONTES DE MIRANDA, 1933, p. 33-50). Seu pensamento mostrava preocupação com o "problema eugênico" (PONTES DE MIRANDA, 1922, p. 535-538) e colova a "cultura eugência" como um dos elementos da "grande obra de disciplina social futura" (PONTES DE MIRANDA, 1981, p. 10).

A busca por um maior dirigismo estatal no pensamento de Pontes de Miranda se dá de diferentes formas. Um dos traços persistentes em seu pensamento é a ideia de integração social, e a intervenção estatal seria uma dos vetores desse processo integrativo (BERCOVICI, 2015, p. 281). Se, por um lado, o jurista alagoano demonstrava uma latente preocupação com os problemas sociais, a questão da

6 Ao contrário disso, entretanto, a visão corrente que se tem de Pontes de Miranda é de um jurista comprometido com a democracia e as garantias individuais no Brasil, sendo um dos juristas mais citados no país até os dias de hoje, e mesmo construções mais sistemáticas de seu pensamento buscam "corrigir" as duras palavras escritas pelo autor nos turbulentos anos do começo do século XX (LIMONGI, 1998). O seu longo itinerário intelectual, contudo, passou por diversas fases e desenvolvimentos e, portanto, deve ser devidamente inserido e analisado em relação ao seu contexto de produção, como se propõe neste estudo em relação às décadas de 1930 e 40. 
raça era vista como um dos instrumentos para a conquista da higienização e da evolução arianizante. Em termos político-jurídicos, devia-se almejar a "política científica" como método para se alcançar a "felicidade pública". Em sua palavras, "Salvo certas medidas de profilaxia, não cuidamos do homem. Pela raça nada se tem feito. Tudo está por fazer. Em muitos Estados da América do Norte, vão as providências aos extremos de castrar os anormais - nós, brasileiros, recebemos imigrantes cegos, imbecis, doentes." (PONTES DE MIRANDA, 1981, p. 1-3).

Naturalmente, no período que compreende as décadas de 20 a 40, as ideias de Pontes de Miranda devem ser inseridas no contexto peculiar do constitucionalismo do entre-guerras, no qual proliferaram as mais diversas propostas de superação do liberalismo político e da democracia parlamentar (MIRKINE-GUETZËVITCH, 1933, p. 21-29). O pensamento de Pontes de Miranda misturava diversas orientações ideológicas para conformar suas posturas jurídico-políticas: defendia posturas por vezes contraditórias e mesclava princípios eugênicos, sindicalistas, positivistas, corporativistas, autoriários, socialistas e liberais (PONTES DE MIRANDA, 1981, p. 13). Durante a ditadura estado-novista, ele produziu poucas obras doutrinárias sobre direito constitucional e teoria do estado, o que torna difícil avaliar os seus julgamentos de valor e as suas convicções políticas sobre a natureza do regime ditatorial iniciado em 1937.

Em 1938, contudo, meses após o golpe do Estado Novo, Pontes de Miranda publica sua obra "Comentários à Constituicção Federal de 10 de novembro de 1937", na qual procurou destacar o caráter essencialmente jurídico de sua interpretação, que se ateria ao que "ela [a constituição] diz, e não ao que a respeito dela foi dito, menos ainda o que se pensou e disse que significaria" (PONTES DE MIRANDA, 1938, p. 9). Ou seja, pode-se afirmar que Pontes de Miranda procurou, de modo bastante hábil, não se comprometer com o establishment autoritário ao tentar produzir uma doutrina "técnica" e "lógica" sobre a Constituição de 1937. Nesse sentido, diz o autor, interpretar é fazer viver, o que não se faz com simpatia ou antipatia: "com a antipatia não se interpreta - ataca-se; porque interpretar é pôr-se do lado do que se interpreta, numa intimidade maior do que permite qualquer ante-posição, qualquer contraste, por mais consentinte, mais 
Novos Estudos Jurídicos

simpático que seja, do intérprete e do texto. Portanto, a própria simpatia não basta". Ao contrário, seria "preciso compenetrar-se do pensamento que esponta nos preceitos jurídicos", tal como ele mesmo teria empreendido no seu trabalho, um estudo de caráter "lógico e técnico da terceira Carta Republicana do Brasil" (PONTES DE MIRANDA, 1938, p. 13).

Como já referido em nota no início dessa análise, o segundo e o quarto volumes previstos da obra anteriormente citada nunca vieram a público, e os seus comentários compreenderiam, respectivamente, do artigo 38 ao 89 e do artigo 124 ao 187. O estudo pormenorizado do segundo tomo compreenderia os artigos da Constituição de 1937, os quais tratam do Poder Legislativo (Câmara dos Deputados, Conselho Federal e Conselho de Economia Nacional) e do Poder Executivo (intitulado simplesmente "Do Presidente da República" no texto constitucional). Enquanto no quarto e no último tomos seriam comentados, dentre outros temas, os tópicos que abordam a ordem econômica, a cultura, a educação, as forças armadas, a segurança nacional, a defesa do Estado, o Tribunal de Segurança Nacional e as emendas à constituição. Pontes de Miranda também jamais chegou a abordar as "Disposições Transitórias e Finais" (que também se incluiriam no quadro esquemático do quarto volume) as quais incluiriam o artigo 178, que dissolvia a Câmara dos Deputados, o Senado Federal, as Assembleias Legislativas dos Estados e as Câmaras Municipais; o artigo 186, que declarava estado de emergência em todo o país; e o artigo 187, que condicionava a entrada em vigor da Constituição de 1937 à apreciação por um plebiscito de abrangência nacional.

De toda forma, do que se tem acesso por meio dos "Comentários" publicados, Pontes de Miranda diz que o art. 174, § $4^{\circ}$ da Constituição de 1937 não excluiu a democracia do Brasil, "a despeito da acentuação simétrica do centro, com que se deu ao Poder Executivo, ou, mais precisamente, ao Presidente da República, uma soma enorme de ingerência e de decisão, na vida do país" (PONTES DE MIRANDA, 1938, p. 15). Isso porque, segundo ele, o seu artigo $1^{\circ}$ assegura que "o poder político emana do povo e é exercido em nome dele, e no interesse do seu bem estar, da sua honra, da sua independência e da sua 


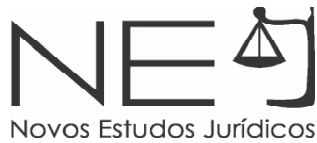

prosperidade" (Constituição de 1937, art. $1^{\circ}$ ). Além disso, observando que seria um anacronismo no século XX uma constituição não se preocupar com a questão social, Pontes de Miranda destaca também o caráter corporativo da Constituição de 1937, especialmente com a criação do Conselho de Economia Nacional e a acentuação de princípios advindos da Constituição de 1934, mas sem o problema do pluripartidarismo. Nesse sentido, tal centralização de poder teria apenas deslocado o presidencialismo dos seus compromissos estaduais e de uma democracia à maneira clássica para salvar o próprio presidencialismo e reestruturar a democracia. Ou seja, conclui o autor, "rigorosamente, a democracia pouco sofreu; o que sofreu foi o Poder Legislativo dos representantes do povo" (PONTES DE MIRANDA, 1938, p. 181).

Para Pontes de Miranda, não há dúvida de que o legislador constituinte de 1937 riscou do seu texto o preceito da separação e da independência dos poderes, além de atribuir ao Executivo a feitura das leis com o nome de decretos-lei. Por outro lado, o autor observa que a guarda da Constituição caberia, segundo seus próprios termos, aos três poderes:

[...] ao Poder Judiciário, na apreciação do caso concreto; ao Presidente da República, a cujo juízo se deixa o submeter, ou não, o julgamento da lei ao reexame parlamentar; finalmente, ao Poder Legislativo, que, por dois terços de votos, se pode manifestar contra a declaração de inconstitucionalidade (PONTES DE MIRANDA, 1938, p. 24-25).

Mais do que legitimar os seus poderes, a Constituição de 1937 colocaria o presidente da República e suas prerrogativas acima dela própria, como se pode inferir dos termos do seu art. 73: "O Presidente da República, autoridade suprema do Estado, coordena a atividade dos órgãos representativos, de grau superior, dirige a política interna e externa, promove e orienta a política legislativa de interesse nacional, e superintende a administração do país" (Constituição de 1937, art. 73). Mais adiante, referindo-se aos estados de emergência ou de guerra, como então se vivia, a Constituição diz que durante sua vigência os "atos praticados [pelo Presidente] em virtude deles não poderão conhecer os juízes e tribunais" (art. 170). Diz ainda que, nesse período, "deixará de vigorar a Constituição nas partes indicadas pelo Presidente da República" (art. 171). 
Na prática, portanto, como teria ocorrido durante todo o Estado Novo, esse último artigo permitiria ao presidente alterar ou mesmo ignorar completamente a Constituição, sem limites ao seu poder. Naquele contexto, em sua obra "A Constituição de dez de novembro: explicada ao povo", Antônio Figueira de Almeida dizia que "sem essa medida o governo poderia ficar desarmado para a realização dos atos necessários para a defesa da ordem pública" (ALMEIDA, 1940, p. 131). Em termos jurídicos, Pontes de Miranda justificaria tal condição do presidente porque o seu poder não seria advindo da Constituição de 1934, mas de uma nova ordem de coisas por ele próprio instituída com a Revolução de 1930. Em suas palavras, diz ele, o ato de outorga da Constituição "foi concebido como ato do Presidente da República dos Estados Unidos do Brasil, mas o Presidente da República, que assim procedia, já exercia o cargo em nome de uma nova ordem de coisas, e não por força da Constituição de 1934, de que lhe adviera, até então, o poder" (PONTES DE MIRANDA, 1938, p. 180).

Face ao exposto, portanto, pode-se afirmar que os juristas Oliveira Viana, Francisco Campos e Pontes de Miranda, por meio de diferentes argumentos, igualmente contribuíram para legitimar a ordem política e jurídica do Estado Novo de Vargas. Em termos políticos, quer atuassem junto ao regime, respectivamente, mais como consultor jurídico ou historiador-sociólogo, ideólogo ou essencialmente como jurista, era consenso entre eles destacar o caráter supostamente democrático e corporativo da Constituição de 1937. Já em termos jurídicos, embora Campos fosse o seu autor e Viana um dos seus grandes entusiastas, caberia a Pontes de Miranda conferir legitimidade jurídica à Constituição de 1937, admitindo ser tecnicamente possível haver um poder constituinte anterior ao povo e acima da própria constituição, qual seja, o Presidente da República. Tais seriam os fundamentos, portanto, da legitimidade político-doutrinária e jurídica da Constituição de 1937, pelo menos nas opiniões de caráter histórico-sociológico ou técnico dos juristas Oliveira Viana, Francisco Campos e Pontes de Miranda. 


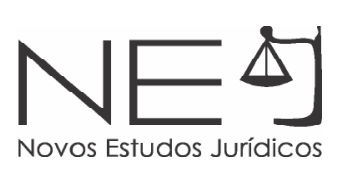

\section{REFERÊNCIAS}

ABREU, Luciano Aronne de. O sentido democrático e corporativo da não-Constituição de 1937. Estudos Históricos, Rio de Janeiro, v. 29, n. 58, p. 461-480, mai./ago. 2016.

ALMEIDA, Antonio Figueira de. A Constituição de dez de novembro: explicada ao povo. Rio de Janeiro: Imprensa Nacional, 1940.

BERCOVICl, Gilberto. O estado integral e a simetrização das classes sociais em Pontes de Miranda: o debate dos anos 1930. Direito \& Práxis, Rio de Janeiro, v. 6, n. 11, p. 272-293, 2015.

CAMPOS, Francisco. O Estado Novo e suas diretrizes. Rio de Janeiro: Imprensa Nacional, 1937.

. Os problemas do Brasil e as grandes soluções do novo regime. Rio de Janeiro: Imprensa Nacional, 1938.

O Estado Nacional. Rio de Janeiro: José Olympio, 1940.

GARGARELLA, Roberto. Latin American Constitutionalism, 1810-2010: the engine room of the constitution. Oxford: Oxford University Press, 2013.

LOPES, José Reinaldo de Lima. Naturalismo jurídico no pensamento brasileiro. São Paulo: Saraiva, 2014.

LIMONGI, Dante Braz. O projeto político de Pontes de Miranda. Estado e democracia na obra de Pontes de Miranda. Rio de Janeiro: Renovar, 1998.

LINS, Augusto E. Estellita. A nova Constituição dos Estados Unidos do Brasil. Rio de Janeiro: J. Konfino, 1938.

MIRKINE-GUETZËVITCH，B. As novas tendências do direito constitucional. São Paulo: Companhia Editora Nacional, 1933.

PONTES DE MIRANDA, Francisco Cavalcanti. Anarchismo, communismo, socialismo. Rio de Janeiro: Adersen, 1933a.

Comentários à Constituição Federal de 10 de novembro de 1937. Tomo I. Artigos

1-37. Rio de Janeiro: Irmãos Pongetti, 1938a.

Comentários à Constituição Federal de 10 de novembro de 1937. Tomo III. Artigos 90-123. Rio de Janeiro: Irmãos Pongetti, 1938b.

. Introdução à política scientifica ou os fundamentos da sciencia positiva do direito.

Rio de Janeiro: Garnier, 1924. 
Os fundamentos actuaes do direito constitucional. Rio de Janeiro: Freitas Bastos,

. Os novos direitos do homem. Rio de Janeiro: Alba, 1933b.

. Preliminares para a revisão constitucional. In: CARDOSO, Vicente Licínio (Org.). À margem da história da república [1924]. Brasília: Editora da Universidade de Brasília, 1981.

Systema de sciencia positiva do direito. v. 2. Investigação scientífica e politica juridica. Rio de Janeiro: Jacinto Ribeiro dos Santos, 1922.

PORTO, Walter Costa. 1937 - Coleção Constituições Brasileiras, v. 4. Brasília: Senado Federal, 2001.

VIANA, Oliveira. Populações meridionais do Brasil: história, organização, psicologia. São Paulo: Monteiro Lobato, 1920. 1923.

A evolução do povo brasileiro. 2. ed. São Paulo: Monteiro Lobato \& Co. Editores,

Instituições políticas brasileiras. v. 2. Metodologia do Direito Público (Os problemas brasileiros da ciência política). 2. ed. Rio de Janeiro: José Olympio, 1955.

Problemas da política objetiva. São Paulo: Companhia Editora Nacional, 1930a.

Problemas da política objetiva. 2. ed. (aumentada). São Paulo: Companhia Editora Nacional, 1947.

. Problemas de direito corporativo. Rio de Janeiro: José Olympio, 1938.

. O idealismo da Constituição. 2. ed. São Paulo: Companhia Editora Nacional, 1930b.

. Problemas de direito sindical. Rio de Janeiro: Max Limonad, 1943. 